MOURA, M.S. et al. Manejo reprodutivo de bovinos na propriedade rural. PUBVET, Londrina, V. 5, N. 9, Ed. 156, Art. 1055, 2011.

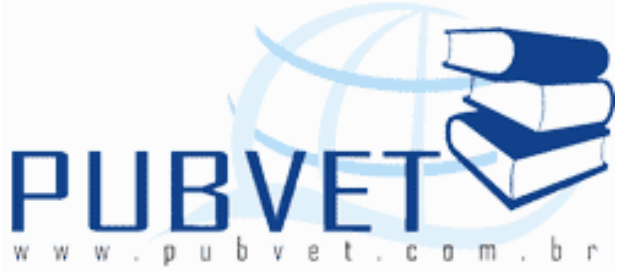

PUBVET, Publicações em Medicina Veterinária e Zootecnia.

\title{
Manejo reprodutivo de bovinos na propriedade rural
}

Mariela Silva Moura ${ }^{1 *}$, Marcela Rodrigues Pedreira Cardoso ${ }^{1}$, Cybele Emília de Araújo $^{1}$, Luciana Pedrosa Iglesias ${ }^{1}$, Maiana Visoná de Oliveira ${ }^{1}$, Gabriella Mamede Andrade ${ }^{1}$, Laerte Pereira de Almeida ${ }^{2}$

${ }^{1}$ Graduanda em Medicina Veterinária, Universidade Federal de Uberlândia. Uberlândia, MG.

${ }^{2}$ Docente da Faculdade de Medicina Veterinária, Universidade Federal de Uberlândia. Uberlândia, MG.

*Autor para correspondência: Rua Ceará, s/n, Bloco 2D, CEP 38400-902, Uberlândia, MG, Brasil. E-mail: marielasmoura@yahoo.com.br

\section{Resumo}

Os desafios reprodutivos incluem uma multiplicidade de fatores, variando da fertilidade dos gametas, mortalidade pós-natal até a infertilidade da cria. A especialidade do conhecimento sobre os fenômenos reprodutivos iniciou-se juntamente com o processo de domesticação das espécies, em especial os bovinos. A importância dos fenômenos reprodutivos teve como conseqüência a origem de processos e métodos que passaram a ser utilizados no cotidiano. A baixa eficiência reprodutiva é um reflexo de distúrbios que afetam negativamente a função fisiológica das fêmeas e dos machos bovinos e também financeiramente para o produtor. Assim, para ampliar os conhecimentos na área, foram destacados alguns fatores importantes que 
MOURA, M.S. et al. Manejo reprodutivo de bovinos na propriedade rural. PUBVET, Londrina, V. 5, N. 9, Ed. 156, Art. 1055, 2011.

influenciam no manejo reprodutivo, como: ciclo estral, fertilização in vitro, transferência de embriões, inseminação artificial, influência do clima na reprodução e manejo da propriedade.

Palavras-chave: bovinos, fertilidade, manejo, reprodução.

\title{
Reproductive management of cattle on the farm
}

\begin{abstract}
The challenges include a variety of reproductive factors, ranging from gamete fertility, mortality, post-natal care to infertility of the offspring. The specialty knowledge on the reproductive phenomena began with the process of domestication of the species, especially cattle. The importance of reproductive phenomena has resulted in the origin of processes and methods that are now used in everyday life. The low reproductive efficiency is a reflection of disturbances that affect negatively the physiological role of females and males cattle and also financially to the producer. Thus, to extend knowledge in this area were highlighted a few important factors that influence the reproductive management, such as the estrous cycle, fertilization in vitro, embryo transfer, artificial insemination, the influence of climate on breeding and management of property.
\end{abstract}

Keywords: cattle, fertility, management, reproduction.

\section{Introdução}

A reprodução pode ser definida como o período entre a concepção da mãe e subseqüente concepção da filha. Conseqüentemente, os desafios reprodutivos incluem uma multiplicidade de fatores, variando da fertilidade dos gametas, mortalidade pós-natal até a infertilidade da cria.

Os conhecimentos envolvidos na reprodução evoluíram de forma muito rápida nas ultimas décadas, originando um ramo especializado denominado por Biologia da Reprodução. A especialidade do conhecimento sobre os 
MOURA, M.S. et al. Manejo reprodutivo de bovinos na propriedade rural. PUBVET, Londrina, V. 5, N. 9, Ed. 156, Art. 1055, 2011.

fenômenos reprodutivos iniciou-se juntamente com 0 processo de domesticação das espécies, em especial os bovinos.

Com o impacto social causado pela utilização dos animais domésticos, tanto para o bem estar da população quanto para representar o poder econômico, deu-se maior importância aos fenômenos reprodutivos e seus possíveis danos. Essa importância teve como conseqüência a origem de processos e métodos que passaram a ser utilizados no cotidiano.

A reprodução de bovinos tem como finalidade a produção de bezerros, que utilizando matrizes que alcançaram a maturidade sexual até o momento de descarte e conseqüente substituição por novilhas, tendo um ciclo repetindo de geração em geração.

Através da aplicação de técnicas pecuárias especializadas pretende-se intensificar as parições, de forma que cada vaca, em idade reprodutiva, produza um bezerro por ano e este deva ser criado de forma sadia e desmamado com bom peso.

A baixa eficiência reprodutiva é um reflexo de distúrbios que afetam negativamente a função fisiológica das fêmeas e dos machos bovinos e também financeiramente para 0 produtor. Alguns fatores que com 0 conhecimento aprimorado, podem interferir nessa eficiência são: ciclo estral, fertilização in vitro, transferência de embriões, inseminação artificial, influência do clima na reprodução e manejo da propriedade.

\section{Revisão de Literatura}

\section{Ciclo estral}

O estro é o período em que a fêmea apresenta vários sinais físicos e aceita a monta, seja esta de um touro, rufião, ou, até mesmo, de outras fêmeas. Esta é a principal manifestação do cio que deve ser percebida pelo técnico observador (SILVA, 2000).

A ausência de estro ou a identificação errônea de cio são problemas que muito afetam a eficiência reprodutiva de bovinos (SILVA, 2000), já que a 
MOURA, M.S. et al. Manejo reprodutivo de bovinos na propriedade rural. PUBVET, Londrina, V. 5, N. 9, Ed. 156, Art. 1055, 2011.

maioria das tecnologias de reprodução empregadas, como inseminação artificial, transferência de embrião e fertilização in vitro, dependem da manifestação do cio e identificação do momento de ovulação para se obter sucesso.

O ciclo estral da vaca é de, em média, 21 dias. As modificações comportamentais e físicas iniciam-se no pré-cio e terminam no pós-cio. O cio propriamente dito, que deve ser identificado com precisão, ocorre entre esses dois intervalos, sendo o momento em que a fêmea aceita a monta (RUAS et al., 2005).

Quanto aos processos fisiológicos que ocorrem no ovário durante o ciclo estral, podemos dividi-lo em duas fases: folicular e luteínica. A fase folicular tem início após a luteólise, que pode ser natural ou exógena (induzida pela prostaglandina). Consequentemente, a concentração sangüínea de progesterona (secretada pelo corpo lúteo) cai bruscamente devido à luteólise. A baixa concentração de progesterona estimula a secreção de $\mathrm{LH}$, que promove a maturação do folículo, o qual secreta estradiol, responsável pela manifestação do cio (BARROS et al., 2004). Após a ovulação, o corpo lúteo é formado e começa a secretar progesterona, que inibe a ação do estrógeno, interrompendo o cio. É a fase luteínica.

As modificações ocorridas no pré-cio, segundo Ruas et al. (2005), são: vulva inchada e brilhante; corrimento vaginal cristalino, transparente e semelhante à clara de ovo; inquietação, nervosismo; cauda erguida; urina e muge constantemente; monta em outras fêmeas, mas não se deixa montar; perda de apetite e diminuição da produção de leite; e afastamento do rebanho.

Durante o cio, a fêmea apresenta os mesmos sinais do pré-cio, com a diferença que, além de montar em outras vacas, também aceita a monta (RUAS et al., 2005).

A manifestação de cio ocorre nas horas mais frescas do dia, por isso é importante realizar duas observações: uma na parte da manhã e outra ao final da tarde. Outra forma de identificar o cio é utilizando rufiões ou fêmeas 
MOURA, M.S. et al. Manejo reprodutivo de bovinos na propriedade rural. PUBVET, Londrina, V. 5, N. 9, Ed. 156, Art. 1055, 2011.

androgenizadas. Aconselha-se a incorporação destes no lote de fêmeas um mês antes da estação de monta (RUAS et al., 2005).

Segundo Barros et al. (2004), nas raças européias, o cio dura cerca de 16 a 18 horas e a ovulação ocorre, em média, entre 10 e 12 horas após o final do cio. Já em zebuínos, o cio dura em média 11 horas.

Alguns cios, porém, não devem ser aproveitados, como o cio do encabelamento, que ocorre entre o terceiro e o quinto mês de gestação. No cio com infecção uterina, o corrimento na vulva é misturado com sangue e pus, neste caso, a infecção uterina irá impedir a prenhez. O cio em novilhas com baixo peso corporal também não deve ser aproveitado para que não prejudique o crescimento e desenvolvimento reprodutivo da fêmea. Além disso, os primeiros cios da novilha são, geralmente, pouco férteis. $O$ cio em vacas com colo sinuoso prejudica a inseminação, pois a cérvix fica torta, impedindo a passagem do aplicador. O cio silencioso é um outro tipo de cio pouco aproveitável, pois o animal não apresenta nenhum sinal externo, mesmo ocorrendo ovulação, passando despercebido pelo observador (RUAS et al., 2005).

"A prostaglandina F2 tem sido o tratamento mais empregado para a sincronização do estro em bovinos. Estudos anteriores mostraram que a maturidade do corpo lúteo no momento da aplicação de prostaglandina influenciou a resposta luteolítica, mas não induziu efetiva luteólise durante 5 a 6 dias após o estro. Além disso, em vacas que ocorreu a luteólise, o estro foi detectado ao longo de 6 dias." (BÓ et al., 2004).

Se a prostaglandina for aplicada quando o folículo dominante estiver no final da fase de crescimento ou no início da fase estática, a ovulação ocorrerá dentro de 3 a 4 dias. Porém, se o folículo dominante estiver no meio ou no final da fase estática, a ovulação do folículo dominante da próxima onda de crescimento irá ocorrer dentro de 5 a 7 dias, para que este novo folículo tenha tempo de se desenvolver até o momento da ovulação. Daí a importância do controle das fases folicular e luteínica na inseminação artificial e transferência 
MOURA, M.S. et al. Manejo reprodutivo de bovinos na propriedade rural. PUBVET, Londrina, V. 5, N. 9, Ed. 156, Art. 1055, 2011.

de embrião em tempo fixo, ou seja, sem a necessidade de deteç̧ão do estro (BÓ et al., 2004).

\section{Fertilização in vitro (FIV)}

A fertilização in vitro (FIV) é uma biotecnologia muito utilizada, que consiste na manipulação da fecundação de óvulos com espermatozóides selecionados, formando um embrião, o qual será implantado em uma vaca receptora (GALUPPO, 2004).

Essa tecnologia tem como objetivo o melhoramento genético, a prevenção de transmissão de doenças infecciosas e o aumento do número de gestações. Para um bom resultado, deve ser realizada em um laboratório adequado (GALUPPO, 2004).

Uma técnica utilizada para a extração dos gametas femininos é a punção folicular orientada por ultra-som, que consiste na retirada do ovócito diretamente do ovário. É muito eficaz, já que independe do período do ciclo estral em que a vaca se encontra e não tem necessidade de tratamentos hormonais para super-ovulação. Além disso, resolve problemas de fertilidade devido a distúrbios na porção tubular do trato genital feminino (VIANA et al., 2001).

Após a extração dos gametas, estes são congelados até o momento da fertilização. Esse processo pode ser do tipo lento ou por vitrificação, em soluções de criopreservação. No primeiro, os ovócitos são submetidos a temperaturas baixas, que diminui gradativamente. Já no congelamento por vitrificação, os gametas são expostos a temperaturas extremamente baixas e logo depositados em palhetas, sofrendo uma queda brusca e rápida de temperatura. Neste último processo, a solução de criopreservação é muito tóxica à zona pelúcida do ovócito em temperaturas acima de zero, exigindo uma rápida manipulação dos ovócitos durante a fertilização. Por isso, a criopreservação por vitrificação é pouco utilizada (GALBINSKI et al., 2003). 
MOURA, M.S. et al. Manejo reprodutivo de bovinos na propriedade rural. PUBVET, Londrina, V. 5, N. 9, Ed. 156, Art. 1055, 2011.

Para reduzir os problemas com a vitrificação, Galbinski et al.(2003) sugere a exposição dos gametas a uma solução com menor concentração de crioprotetores, menor tempo de exposição e a mistura desses crioprotetores com outros menos tóxicos.

Os procedimentos realizados em um laboratório de fertilização in vitro devem ser executados com muita atenção e responsabilidade, desde a obtenção dos ovócitos até a transferência dos embriões. Qualquer descuido pode causar grande prejuízo nos resultados obtidos pelo laboratório (GALUPPO, 2004).

O laboratório ideal para a realização da fertilização in vitro foi descrito por Galuppo (2004). Deve constar um ambiente asséptico e com temperatura de aproximadamente $25^{\circ} \mathrm{C}$. Essa temperatura é um dos fatores mais importantes, pois, segundo Silva (2000), a temperatura ambiente exerce influência direta na capacidade de sobrevivência in vitro dos espermatozóides, principalmente de touros de raças européias.

Além disso, o ar do laboratório deve ser filtrado, eliminando todos os tipos de resíduos, desde partículas de poeira até microorganismos antes da entrada do ar na sala onde é realizada a fertilização in vitro. Além disso, o número de pessoas dentro do laboratório influencia muito na qualidade do ar. Quanto às roupas, devem ser de tecidos que não liberem fibras. É importante, também, evitar o uso de cosméticos (GALUPPO, 2004).

\section{Transferência de embrião}

Apesar da transferência de embrião ser uma tecnologia amplamente utilizada no mundo, o seu sucesso não é unânime. Adquirindo maiores conhecimentos da função ovariana, pode-se obter um controle folicular, o que facilita o processo. Isso possibilita iniciar o tratamento superovulatório no momento ideal (BÓ et al., 2004). Se a super-ovulação for realizada no estágio inicial do ciclo estral, há um aumento de embriões transferíveis (DEMCZUK et al., 1998). 
MOURA, M.S. et al. Manejo reprodutivo de bovinos na propriedade rural. PUBVET, Londrina, V. 5, N. 9, Ed. 156, Art. 1055, 2011.

A transferência de embrião é eficaz para amenizar os efeitos do estresse calórico sobre a reprodução. Se a transferência realizada for a fresco, é recomendado que o embrião tenha aproximadamente sete dias, pois já terá superado a fase de maior estresse calórico (PEREIRA, 2005).

Vários são os fatores que influenciam no sucesso da transferência de embrião, como anormalidades cromossômicas, idade e qualidade dos embriões transferidos, método e local da transferência, sincronia de estro doadora receptora, estado nutricional, níveis séricos de progesterona na receptora e estresse calórico (GALIMBERTI, et al., 2001).

A taxa de prenhez é proporcional ao tamanho do corpo lúteo, que pode ser identificado por palpação via retal, ou seja, quanto maior o corpo lúteo, melhor a taxa de prenhez (DEMCZUK et al., 1988). Esta depende de uma integração adequada entre o embrião, o ambiente uterino e o corpo lúteo (GALIMBERTI et al., 2001). O embrião, após a concepção, é estimulado pela progesterona e produz um anti-luteolítico interferon trofoblástico, que inibe os mecanismos de destruição do corpo lúteo, mantendo a gestação. O embrião, porém, pode não receber estímulos suficientes para a produção desse hormônio, prejudicando a taxa de prenhez da receptora (GALIMBERTI et al., 2001).

Segundo Silva (2000), as vacas doadoras seriam superovuladas e mantidas em conforto térmico até ser realizada a coleta dos embriões, que seriam, no 70 dia, transferidos para receptoras bem adaptadas ao calor. Ou então, o embrião seria congelado e transferido em épocas de temperaturas mais amenas.

Bó et al. (2004) explicam o tratamento de "Ovsynch", que consiste na administração de hormônio liberador de gonadotrofina (GnRH) e prostaglandina em receptoras de embriões produzidos in vivo ou in vitro. A administração de GnRH induzirá um pico de $\mathrm{LH}$, resultando na ovulação e emergência de uma nova onda de crescimento folicular após 2 dias. A luteólise é induzida pela administração de prostaglandina 7 dias após a primeira dose 
MOURA, M.S. et al. Manejo reprodutivo de bovinos na propriedade rural. PUBVET, Londrina, V. 5, N. 9, Ed. 156, Art. 1055, 2011.

de GnRH e uma segunda dose deste último é administrada, causando outro pico de LH, com nova ovulação. Após essa segunda ovulação, as receptoras que apresentarem corpo lúteo são selecionadas para receberem a transferência direta de um embrião descongelado, sem a detecção de cio. Estudos mostram que a taxa de prenhez em fêmeas submetidas a esse tratamento é maior que naquelas tratadas com prostaglandina e submetidas a observação de estro por 5 dias.

\section{Inseminação artificial}

O conceito de inseminação segundo Ruas et al. (2005) é: "deposição mecânica do sêmen no aparelho reprodutivo da fêmea através de equipamentos apropriados. A fecundação acontece sem a interferência do homem. Os resultados da inseminação dependem, basicamente, do manejo adotado na fazenda, da qualidade do sêmen utilizado e da eficiência do inseminador".

Durante a monta, o touro deposita milhões de espermatozóides na vagina da fêmea, porém, poucos são os que conseguem atingir a ampola da tuba uterina, onde ocorre a fecundação, já que a grande maioria é barrada na cérvix. Na inseminação artificial, esse obstáculo é ultrapassado com o aplicador e o sêmen é depositado direto no corpo uterino (SARTORI, 2004).

Diversas são as vantagens dessa tecnologia. Dentre elas, Ruas et al. (2005) cita melhoramento genético e reprodutivo, redução da dificuldade em partos, cruzamento entre raças, prevenção de acidentes com as fêmeas, aumento do número de descendentes de um bom reprodutor, padronização do rebanho, uso de touros após a morte, melhor controle sanitário da reprodução.

A seleção de touros doadores de sêmen comprovadamente superiores garante um melhoramento genético, com aumento na produção de leite ou carne. Os touros, também, devem ter descendentes adequados para nascer em novilhas, sem prejudicá-las com problemas de parto (RUAS et al., 2005). 
MOURA, M.S. et al. Manejo reprodutivo de bovinos na propriedade rural. PUBVET, Londrina, V. 5, N. 9, Ed. 156, Art. 1055, 2011.

O cruzamento entre raças taurinas e zebuínas, na monta natural, dificilmente ocorre, devido à dificuldade de adaptação climática das raças européias. Com a inseminação, esse cruzamento torna-se viável, além de prevenir acidentes com a fêmea, que muitas vezes ocorre na monta natural, principalmente em novilhas, por um touro muito pesado (RUAS et al.,2005).

A quantidade de descendentes gerados por um touro em monta natural, é consideravelmente inferior ao número de bezerros provenientes de seu sêmen quando se utiliza inseminação artificial. Anualmente, a campo, em um regime de monta controlada, um touro cobre no máximo 100 vacas, produzindo no máximo 400 descendentes em seu tempo de vida. Com a inseminação, esse número aumenta para 500.000 filhos e seu sêmen pode ser estocado e utilizado mesmo após sua morte (RUAS et al., 2005).

A padronização do rebanho pela utilização de poucos reprodutores em um grande número de vacas facilita a sua comercialização. Sem falar na prevenção de doenças que podem ser transmitidas para a fêmea ou para o touro durante a monta natural (RUAS et al., 2005).

O protocolo de "Ovsynch" é muito eficaz na inseminação artificial em tempo fixo (sem detecção de estro) em vacas, sendo pouco eficiente em novilhas. Isso ocorre porque o tratamento com GnRH nem sempre induz a ovulação e formação luteínica do folículo dominante em novilhas. A segunda onda de crescimento do folículo só ocorre se houver essa primeira ovulação. Logo, a ovulação com o segundo GnRH fica comprometida se o primeiro GnRH não induzir a ovulação (BÓ et al., 2005).

Quanto à prática da inseminação, Ruas et al. (2005) recomenda que fêmeas observadas em cio pela manhã, sejam inseminadas na tarde do mesmo dia. Já as vacas e novilhas observadas em cio à tarde, devem ser inseminadas na manhã do dia seguinte. 
MOURA, M.S. et al. Manejo reprodutivo de bovinos na propriedade rural. PUBVET, Londrina, V. 5, N. 9, Ed. 156, Art. 1055, 2011.

\section{Efeitos climáticos na reprodução}

Os efeitos climáticos causam sobre o animal um estresse intenso, provocando uma série de alterações metabólicas. Essas alterações consistem basicamente no desvio de fontes energéticas para a manutenção da temperatura corporal, ou seja, ocorre uma queda considerável na produção de leite e carne, afetando, também, o desempenho reprodutivo (PEREIRA, 2005).

A detecção do estro também é muito prejudicada pelas altas temperaturas dos climas tropical e subtropical. Experimentos mostram que, nas vacas mantidas expostas às radiações solares, há aumento nos níveis de progesterona e de corticóides na fase luteínica, enquanto o de estradiol é baixo em relação às vacas isentas de estresse calórico (SILVA, 2000). Como a progesterona é um hormônio inibidor das reações responsáveis pela manifestação de cio, pode-se, assim, demonstrar a interferência das temperaturas elevadas na identificação do estro.

Segundo Silva (2000), a temperatura intra-uterina aumenta quando a vaca é submetida a altas temperaturas ambiente, reduzindo a taxa de concepção. Além disso, há uma redução do fluxo sangüíneo nesse órgão com conseqüente diminuição de fornecimento de água, eletrólitos, nutrientes e hormônios ao útero, podendo causar morte do embrião no início da gestação.

O resfriamento de fêmeas nos primeiros dias de prenhez, quando o embrião é mais susceptível ao estresse calórico, é eficaz na taxa de gestação, mas essa técnica não previne totalmente o aborto, já que o estresse calórico pode afetar o feto até mesmo no final da gestação (PEREIRA, 2005).

Uma forma de reduzir os efeitos das altas temperaturas na reprodução é realizando inseminação e colocando a estação de monta em épocas do ano de climas mais amenos, resultando em melhor desempenho reprodutivo dos bovinos, viabilizando os sistemas especializados em regiões tropicais e subtropicais. Evitar o fornecimento de alimentos e a movimentação dos animais nas horas mais quentes do dia também é uma boa alternativa para reduzir o estresse calórico (PEREIRA, 2005). 
MOURA, M.S. et al. Manejo reprodutivo de bovinos na propriedade rural. PUBVET, Londrina, V. 5, N. 9, Ed. 156, Art. 1055, 2011.

O estresse pelo calor na fase embrionária de blastocisto reduz significativamente o peso do embrião, podendo causar sua morte. A sensibilidade do embrião nessa fase, porém, é menor que a nos primeiros sete dias de vida (SILVA, 2000).

A temperatura ambiente afeta significativamente $\mathrm{opH}$ do sêmen e o volume do ejaculado de touros das raças européias. Os efeitos térmicos na qualidade dos espermatozóides é mais evidente nas primeiras semanas de espermatogênese. Tais efeitos estão presentes inclusive em touros de raça zebuína (SILVA, 2000).

\section{Manejo da Propriedade}

O primeiro passo para obter sucesso na criação de gado, seja ele para corte ou leite, é fazer instalações adequadas. Separar os animais em piquetes; identificá-los com números; fazer uma ficha para cada animal, anotando as vacinações, data de nascimento, partos, etc.; disponibilizar sombreamentos e água nas pastagens são fatores que muito influenciam no desempenho reprodutivo do animal (PEREIRA, 2005).

A separação do rebanho em lotes de acordo com sua categoria é o primeiro passo para uma boa rentabilidade. Uma opção seria piquetes de machos desmamados, fêmeas desmamadas, novilhas, garrotes, bois, vacas primíparas, vacas multíparas paridas, vacas solteiras, vacas amojadas e rufiões (RUAS et al., 2005). Essa separação evita que enfermidades de bovinos adultos contagie bezerros, evita, também, gestações indesejáveis e facilita o manejo geral do rebanho (SILVA, 2000).

As fêmeas amojadas devem ser conduzidas pro piquete maternidade um mês antes do parto e permanecer lá até alguns dias após o parto. Os bezerros recém-nascidos devem ter seus umbigos curados e mamar o colostro nas primeiras horas após o nascimento. A lactação deve ser interrompida dois meses antes do parto, favorecendo, assim, o nascimento de crias mais fortes, preparação corporal para o parto e desenvolvimento de colostro de boa 
MOURA, M.S. et al. Manejo reprodutivo de bovinos na propriedade rural. PUBVET, Londrina, V. 5, N. 9, Ed. 156, Art. 1055, 2011.

qualidade. As novilhas, também separadas em lotes homogêneos, estão prontas para reproduzir quando atingem o peso mínimo adequado, que varia entre as raças. Após o parto, a vaca deve ter um descanso de no mínimo 45 dias para a próxima gestação, tempo necessário para a regressão uterina ao tamanho normal e limpeza das paredes internas. Quanto ao desmame, é recomendado que seja feito entre 7 e 8 meses de idade em gado de corte e 10 meses em gado de leite, quando machos e fêmeas devem ser separados (RUAS et al., 2005).

Segundo Ruas et al. (2005), o exame ginecológico anual de todas as fêmeas em idade reprodutiva é de grande relevância, pois permite a seleção daquelas aptas à reprodução e o tratamento ou descarte das demais.

No planejamento do manejo de fazendas, deve-se dar importância à arborização das pastagens, pois as vacas, em sua maioria, preferem as sombras naturais às estruturas feitas pelo homem. É um modo eficiente de protegê-las da radiação solar, além de reduzir a temperatura através da evaporação de suas folhas e permitir movimentação do ar sob sua copa. 0 bebedouro e os cochos de alimentação devem estar sob a sombra, ou próximos dela, para evitar que os animais a abandonem nas horas mais quentes do dia (PEREIRA, 2005).

A arborização, entretanto, deve ser adaptada e apresentar características de crescimento adequadas. Indica-se árvores frondosas, com folhas perenes, altura mínima de 3 metros e boa ventilação. Esta última característica é importante na secagem rápida do solo em dias úmidos ou chuvosos, evitando o acúmulo de barro, com conseqüente redução na incidência de infecções podais e bernes. As árvores, além disso, devem apresentar um crescimento rápido, adaptação ao ambiente, tolerância ao ataque de insetos e doenças, ausência de efeitos tóxicos para o animal, e, caso produza frutos, estes devem ser de pequeno volume, para evitar que o animal engasgue ao ingeri-los. (PEREIRA, 2005). 
MOURA, M.S. et al. Manejo reprodutivo de bovinos na propriedade rural. PUBVET, Londrina, V. 5, N. 9, Ed. 156, Art. 1055, 2011.

Enquanto as árvores crescem, recomenda-se a instalação de sombreamentos artificiais. As sombras móveis podem ser baseadas na utilização de tela de fibra sintética. A vantagem desse material é a resistência aos raios ultravioletas. Deve ter uma leve inclinação para evitar o acúmulo da água de chuva sobre a rede. As sombras portáteis podem ser deslocadas quando preciso, como no caso de formação de lamas e buracos no local da instalação. Se houver preferência por uma sombra mais estável, a instalação deve ser construída no sentido leste-oeste; para uma sombra mais variável, sugere-se a instalação no sentido norte-sul. Esta é preferível nas regiões de verão muito chuvoso (PEREIRA, 2005).

As sombras permanentes são recomendadas para regiões onde ocorre estresse calórico durante todo o ano e devem ser construídas com um material de maior durabilidade. São mais complexas e de maior custo, recomendadas para sistemas de confinamento. Devem possuir inclinação e altura correta, o ideal é a parte mais baixa possuir no mínimo $4 \mathrm{~m}$ de altura. $\mathrm{O}$ eixo longitudinal da estrutura deve ser na orientação leste-oeste, para permitir um sombreamento durante todo o dia. Se as vacas não estiverem confinadas, a melhor posição da estrutura é norte-sul, para facilitar a secagem da área abaixo do sombreamento pelo sol (PEREIRA, 2005).

Uma ventilação adequada também é muito importante, pois proporciona a remoção de gases, poeiras, odores, microorganismos causadores de doenças, umidade e previne o acúmulo de calor. A dosagem de ventilação, porém, deve ser adequada, pois o excesso é extremamente prejudicial, causando queda na resistência imunológica dos animais, favorecendo a manifestação de doenças. A ventilação pode ser natural ou mecânica (PEREIRA, 2005).

A ventilação natural está associada à altura dos estábulos e consiste, assim como a ventilação mecânica, na troca de calor entre as moléculas de ar. Quando a ventilação natural não é suficiente para dissipação de calor, é necessário o emprego de ventiladores ou de sistema de resfriamento 
MOURA, M.S. et al. Manejo reprodutivo de bovinos na propriedade rural. PUBVET, Londrina, V. 5, N. 9, Ed. 156, Art. 1055, 2011.

evaporativo para resfriar os animais, melhorando as condições de conforto (PEREIRA, 2005).

\section{Conclusão}

Em suma, além do aprimoramento do conhecimento dos aspectos citados, outras técnicas importantes que as propriedades também podem adotar, visando à melhoria da eficiência reprodutiva são: a sexagem do sêmen, clonagem, influência da nutrição e sanidades na reprodução.

Não se pode esquecer a importância da participação do clínico veterinário no processo reprodutivo que é fundamental e, que o mesmo deve estar profissionalmente bem preparado.

\section{Referências}

BARROS, Ciro Moraes; ERENO, Ronaldo Luiz Avanços em Tratamentos Hormonais Para a Inseminação Artificial com Tempo Fixo (IATF) em Bovinos de Corte. R. Acta Scientiae veterinariae, v.32, p.23-34, 2004.

BÓ, G. A.; MORENO, D.; CUTAIA, L.; BARUSELLI, P.S.; REIS, E. L. Manipulação Hormonal do Ciclo Estral em Doadoras e Receptoras do Embrião Bovino. R. Acta Scientiae veterinariae, v.32, p.1-22, 2004.

DEMCZUK, Estefano; KOZICKI, Luiz Ernandes; PONTELLI, Edílson Santos; SALLES, Jackson Oliveira. Transferência de Embrião em Vacas da Raça Simental na Região Noroeste do Paraná e Sul do Mato Grosso do Sul. R. Brazilian Journal of Veterinary Research and Animal Science, v.35, n.4, p.174-177, 1998.

GALBINSKI, Sérgio; MIKICH, Adriana Bos-; FERRARI, Arnaldo Nicola Viabilidade e Fertilização In Vitro de Oócitos Bovinos Após Vitrificação. R. Brasileira de Ginecologia e Obstetrícia, vol. 25, nº. 8, 2003.

GAlimberti, A. M. et al. Taxa de Gestação e Níveis Plasmáticos de Progesterona, em Receptoras de Embrião Bovino, Tratadas com Buserelina Após a Inovulação. Revista Brasileira de Zootecnia, v. 30, n. 2, 2001.

GALUPPO, Adrea Giannotti Controle de Qualidade de Laboratórios de Produção de Embriões. R. Acta Scientiae veterinariae, v.32, p.51-54,2004.

PEREIRA, Jonas Carlos Campos Fundamentos de Bioclimatologia Aplicados à Produção Animal. Editora FEPMVZ, 195 páginas, 2005.

RUAS, R.R. et al. Manual de Inseminação Artificial em Bovinos. Edição de 2005, 46 páginas. 
MOURA, M.S. et al. Manejo reprodutivo de bovinos na propriedade rural. PUBVET, Londrina, V. 5, N. 9, Ed. 156, Art. 1055, 2011.

SARTORI, R. Fertilização e Morte Embrionária em Bovinos. R. Acta Scientiae veterinariae, v.32, p.35-50, 2004.

SILVA, Roberto da. Introdução à Bioclimatologia Animal. Editora Nobel, 2000, 286 páginas.

VIANA, J.H.M.; CAMARGO, L.S.A.; FERREIRA, A.M.; SÁ, W.F.; JÚNIOR, A.P.M. Nascimento de Bezerra Gerada com Auxílio de Técnicas de Punção Folicular e Fertilização In Vitro no Estado de Minas Gerais. R. Arquivo Brasileiro de Medicina Veterinária e Zootecnia, vol. 53, n04, 2001. 